\title{
The interaction of woody biomass with bituminous coal in their blends
}

\author{
Ho Young Park, Yoon Hwa Park ${ }^{\dagger}$, Young Joo Kim, Hyun Hee Kim, Sang Bin Park \\ KEPRI, 105 Munji-Ro, Yuseong-Gu, Daejeon 34056, Republic of Korea
}

\begin{abstract}
This paper describes the non-isothermal pyrolysis of wood pellet and saw dust, and their blends with bituminous coal. The blends showed the distinct, two peaks in thermogravimetric curves, and the first peak came from the biomass pyrolysis and the second one came from the coal pyrolysis. The interaction in the blend was evaluated in terms of the maximum rate of weight loss, characteristic temperatures, char yields, and the calculated and experimental thermogravimetric curves. The activation energies and frequency factors for the blends were obtained with the multi-stage, Coats and Redfern method. The respective activation energies of 73 and $67 \mathrm{~kJ} / \mathrm{mol}$ and the frequency factors of 725,100 and $65,262 \mathrm{~min}^{-1}$ were obtained for the present wood pellet and saw dust samples. The thermogravimetric study shows that there is no significant interaction between the present biomass and coal in the blends, and the pyrolysis behavior can be described with the additive rule.
\end{abstract}

Keywords: Biomass, Coal, Pyrolysis, Saw dust, TGA, Wood pellet

\section{Introduction}

There is considerable interest in the use of biomass for power generation in Korea. This is due to the fact that the use of biomass is neutral for $\mathrm{CO}_{2}$ emissions, that is, the combustion of biomass does not produce any $\mathrm{CO}_{2}$. Recently, many counties have initiated various incentive to encourage the utilization of biomass for power generation. With Renewable Energy Portfolio Standard (RPS) started in 2012, the power generation companies in Korea have to generate certain amounts of electric power by using the new and renewable energy resource. According to RPS, the power generation by the new and renewable energy resource was $2 \%$ of the total power generation in 2012, and it will reach $12 \%$ in 2024. Among the new and renewable energy source, the co-firing of biomass with coal has been used in the coal-fired power plant in order to meet with the requirement of RPS. The wood pellet (WP) and saw dust (SD) has been used in many coal-fired power plants in Korea.

There are differences in the combustion characteristics of coal and biomass, and it is mainly due to the fact that the volatile portion of biomass is higher than that of coal. The ratio of volatile to fixed carbon for biomass is typically greater than 4.0, whereas for coal it is always less than $1.0[1,2]$. In the biomass-coal blend, the pyrolysis of biomass occurs earlier with the higher portion of volatile comparing to coal, so the combustion of biomass occurs very rapidly, and subsequently affects the combustion of coal in the blend. Since the role of biomass pyrolysis is quite important to describe the overall combustion characteristics of the blend, there have been many Thermo-gravimetric analyzer (TGA) studies on the pyrolysis characteristics of the biomass-coal blend and the interaction in the blend [3-14]. The understanding from the TGA studies would provide the basic knowledge for describing the combustion of biomass-coal blends in a utility boiler. Concerning the pyrolysis of biomass-coal blend, there have been different points of view on the interaction between biomass and coal in the blend. Some studies have reported no-interaction between the components in the biomass-coal blend [3-9], while other studies present the opposite results [10-14].

To evaluate the extent of interaction in the biomass-coal blends, the char yields and characteristic temperatures were employed whether the interaction in the blend occurs or not [5-6]. Some studies used the difference between the experimental and theoretical thermogravimetric (TG) and differential thermogravimateric (DTG) curves, and another studies used the maximum rate of weight DTG and its temperature [7-9]. On the while, Wu et al. [15] investigated the effect of lignocelluloses components
This is an Open Access article distributed under the terms of the Creative Commons Attribution Non-Commercial License (http://creativecommons.org/licenses/by-nc/3.0/) which permits unrestricted non-commercial use, distribution, and reproduction in any medium, provided the original work is properly cited.
Received December 26, 2016 Accepted March 13, 2017

${ }^{\dagger}$ Corresponding author

Email: jhoin@naver.com

Tel: +82-42-865-5641 Fax: +82-42-865-5679

Copyright (C) 2017 Korean Society of Environmental Engineers 
(cellulose, hemicelluloses and lignin) on the synergistics of the blends of individual components and bituminous coal. Depending on the temperature ranges and blending ratio, each component showed the positive or negative synergistic effects on the thermal behavior of bituminous coal. They concluded that three components compete each other to generate positive or negative synergistics on the pyrolysis of biomass-coal, and it may result in the conflicting results on the existing of synergistc effect.

In the present study, the temperature programmed, non-isothermal thermogravimetric analysis was adopted to study the pyrolysis behavior of the biomass-coal blend as well as the interaction between biomass and coal in the blend. WP and SD were blended with bituminous coal at the ratios of 20:80, 40:60, 60:40, 80:20 for biomass and coal on the basis of weight percentage. The interaction of three biomass (WP and SD) with bituminous coal in their blends was evaluated with all TGA experimental parameters, that is, the maximum rate of weight loss, characteristic temperatures, char yields, and the calculated TG curves. The kinetic data for the blends were obtained with the multi stage Coats and Redfern method, and the lignocellulose components in the blends were calculated for all blends, and the positive and negative effects of them on the interaction was discussed. In the present study, the interaction between the individual components in the blends was investigated in terms of the kinetic data, char yield as well as the characteristic data from TGA curves. The extent of interaction was quantified with the numeric value, and it is significantly addressed in this study.

\section{Experimental}

\subsection{Materials}

Glencore coal which is Austrailian bituminous coal was collected from a $500 \mathrm{MW}$ power plant which is co-firing WP with coal, and the coal was ground and sieved to be less than $75 \mu \mathrm{m}(200$ mesh). The biomass types used in the present study were WP

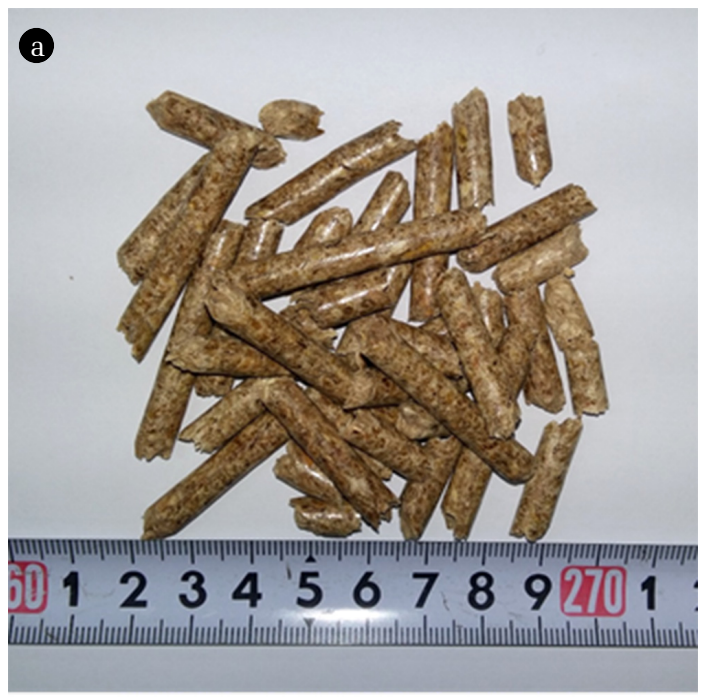

Fig. 1. Photo of (a) wood pellet and (b) saw dust.
Table 1. Properties of Biomass and Coal

\begin{tabular}{lccr}
\hline \multicolumn{1}{c}{ Material } & WP & \multicolumn{1}{c}{ SD } & \multicolumn{1}{c}{ Coal } \\
\hline Proximate analysis (wt.\%) & & & \\
\hline moisture & 7.11 & 7.78 & 9.81 \\
ash & 1.57 & 7.98 & 8.53 \\
volatile & 80.5 & 72.6 & 34.52 \\
fixed carbon & 10.82 & 11.64 & 47.13 \\
\hline Ultimate analysis (wt.\%) & & & \\
\hline C & 54.11 & 55.70 & 78.58 \\
H & 6.83 & 6.69 & 5.25 \\
O & 38.45 & 37.58 & 13.74 \\
N & 0.6 & 0.01 & 2.01 \\
S & 0.01 & 0.01 & 0.42 \\
\hline Heating value (kcal/kg) & 4,409 & 4,308 & 6,761 \\
\hline Lignocellulosic composition (wt.\%) & & & \\
\hline acetone solution & 1.01 & 0.60 & \\
hot-water extract & 14.26 & 13.25 & \\
ligin & 33.27 & 26.00 & \\
hemicellulose & 20.32 & 22.29 & \\
cellulose & 31.14 & 37.85 & \\
\hline
\end{tabular}

and SD, and their size was prepared to be less than $75 \mu \mathrm{m}$. The biomass-coal blends were made with the blending ratios of 20:80, $40: 60,60: 40,80: 20$ on the basis of weight percentage. Ultimate and proximate analysis, chemical ingredients of coal and biomass were given in Table 1. Fig. 1(a) and 1(b) show the photo of WP and SD.

\subsection{Thermogravimetric Experiment}

TGA (Setsys Evolution, Setaram) was used to characterize the pyrolysis behavior of the present biomass-coal blends under the

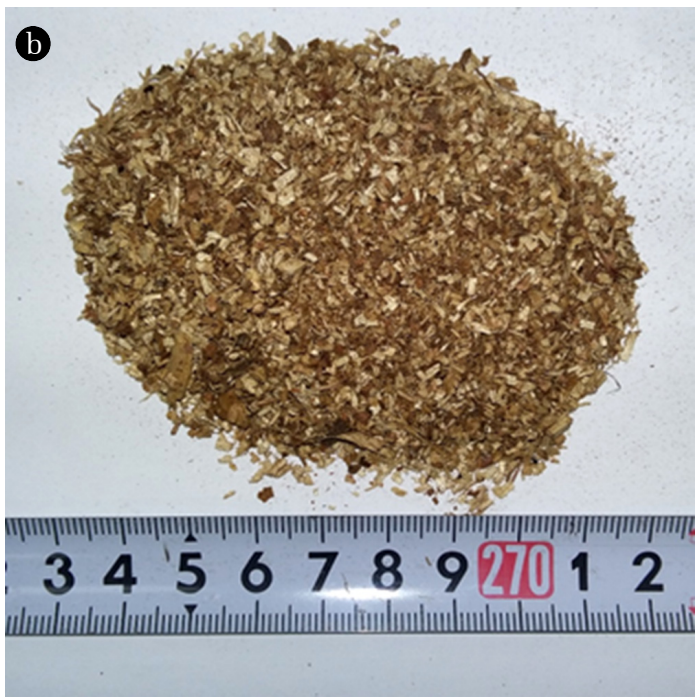


temperature programmed, non-isothermal heating mode. The heating rate used in the present TGA tests was $10^{\circ} \mathrm{C} / \mathrm{min}$ from room temperature to $1,000^{\circ} \mathrm{C}$. To minimize the experimental error, the diffusion effect on the sample was checked with several sample weight and reaction flow rates. Approximately $10 \mathrm{mg}$ sample and $\mathrm{N}_{2}$ of $100 \mathrm{~mL} / \mathrm{min}$ were used in all TGA tests. Those sample weight and gas flow were obtained from the preliminary tests to ensure the chemically controlled condition.

\subsection{Kinetic Analysis}

In analyzing the non-isothermal kinetic parameters for the pyrolysis of solid fuel, the kinetic equation is written as

$$
\frac{d x}{d t}=\operatorname{Aexp}^{-\frac{E}{R T}}(1-x)^{n}
$$

where $x$ is the conversion fraction of fuel sample, $t$ is the time in minutes, and $x$ is given by

$$
x=\frac{W_{i}-W}{W_{i}-W_{f}}
$$

$W, W_{i}, W_{f}$ represent the instantaneous, initial and final weights of the sample, respectively. In the pyrolysis experiments, $W_{i}$ was taken at the temperature of $120^{\circ} \mathrm{C}$ after the moisture evolution and $W_{f}$ was taken at $1,000^{\circ} \mathrm{C}$. The value of $W_{f}$ means the sum of fixed carbon and ash in the sample.

For a constant heating $\beta=d T / d t$, Eq. (1) is rearranged as follows:

$$
\frac{d x}{d T}=\frac{1}{\beta} \operatorname{Aexp}^{-\frac{E}{R T}}(1-x)^{n}
$$

For most reactions, the value of $2 \mathrm{RT} / \mathrm{E}$ is very small $(2 \mathrm{RT} / \mathrm{E}$ «1) and the process of pyrolysis is assumed to be first order reaction $(n=1)$. The approximate integration of Eq. (3) gives the Coats and Redfern equation and it is given as:

$$
\ln \left[\frac{-\ln (1-x)}{T^{2}}\right]=\ln \frac{A R}{\beta E}-\frac{E}{R T}
$$

In this equation, the activation energy (E) and frequency factor (A) are obtained from the slope (-E/R) and intercept of the regression line, respectively.

To describe the thermal behavior of biomass-coal blends, the first order, multi-stage reaction scheme has been frequently used [16-18] The present study adopted this reaction scheme, namely, the multi stage, Coats and Redfern equation, and the kinetic parameters for each stage were obtained for the present samples. The experimental conversion curves of the pyrolysis for the samples were again fitted with the obtained kinetic parameters to ensure the validity of the present kinetic analysis.

The kinetic parameters obtained from Coats and Redfern equation were used to ensure the validity of the present kinetic analysis. The integration of Eq. (3), and it is given as follows:

$$
x=1-\exp \left[-\frac{A R T^{2}}{\beta E} \exp ^{-\frac{E}{R T}}\left(1-\frac{2 R T}{E}\right)\right]
$$

The experimental conversion data were compared with the conversion data (x) of Eq. (5) obtained with the values of A and E values from Eq. (4).

\section{Results and Discussion}

\subsection{Single Fuels}

The TG and the DTG curves for coal, WP and SD are shown in Fig. 1(a) and 1(b), respectively. After the moisture evolution up to the temperature of $150^{\circ} \mathrm{C}$, the pyrolysis starts at $354^{\circ} \mathrm{C}$ for coal, $206^{\circ} \mathrm{C}$ and $187^{\circ} \mathrm{C}$ for WP and SD, respectively. WP and SD exhibit the similar shapes of TG and DTG curves. Their peaks of about 8.6 wt.\%/min in DTG curves occur around $351^{\circ} \mathrm{C}$ and the values are much higher than $1.66 \mathrm{wt} \% / \mathrm{min}$ of bituminous coal. The DTG curves of WP and SD in Fig. 2(b) appear to be a typical shape of woody biomass, showing a rapid weight loss originated from the pyrolysis of hemicelluloses and cellulose, and then the subsequent weight losses from the lignin pyrolysis. It has been reported that the pyrolysis for woody biomass starts around $200^{\circ} \mathrm{C}$ with hemicelluloses in the parent biomass and reaches the peak around $364^{\circ} \mathrm{C}$, while the decomposition of lignin occurs around $200-900^{\circ} \mathrm{C}$ and peaks around $360-407^{\circ} \mathrm{C}$ [19].

To characterize the pyrolysis behavior in TG and DTG curves,

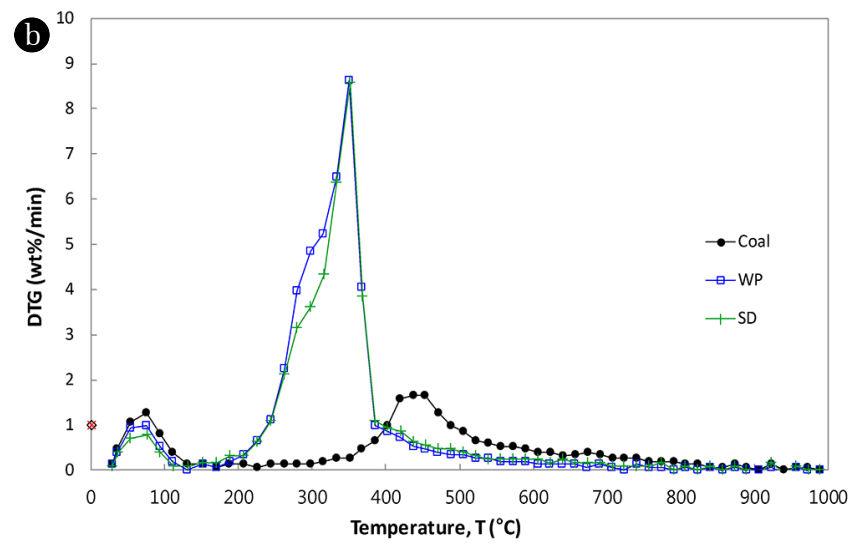

Fig. 2. TG and DTG curves for biomass and coal. 
Table 2. Characteristic Parameters for the Present Biomass-coal Blends

\begin{tabular}{|c|c|c|c|c|c|c|c|c|}
\hline \multicolumn{2}{|c|}{ Pyrolysis } & \multirow{2}{*}{$\frac{\text { IT }\left({ }^{\circ} \mathbf{C}\right)}{354}$} & \multirow{2}{*}{$\frac{\mathrm{PT}_{\mathbf{1}}\left({ }^{\circ} \mathbf{C}\right)}{445}$} & \multirow{2}{*}{$\frac{\mathbf{R}_{\mathbf{1}} \text { (wt.\%/min) }}{1.66}$} & \multirow[t]{2}{*}{$\mathrm{PT}_{2}\left({ }^{\circ} \mathrm{C}\right)$} & \multirow[t]{2}{*}{$\mathbf{R}_{2}$ (wt.\%/min) } & \multirow{2}{*}{$\frac{\text { BT }\left({ }^{\circ} \mathrm{C}\right)}{698}$} & \multirow{2}{*}{$\begin{array}{c}\text { char yield (wt.\%) } \\
60.8\end{array}$} \\
\hline Coal & 100 & & & & & & & \\
\hline \multirow{5}{*}{$\begin{array}{l}\text { wt.\% } \\
\text { of WP }\end{array}$} & 20 & 248 & 351 & 1.87 & 445 & 1.37 & 632 & 52.5 \\
\hline & 40 & 230 & 351 & 3.61 & 445 & 1.16 & 612 & 42.6 \\
\hline & 60 & 213 & 351 & 5.14 & 420 & 1.05 & 580 & 35.7 \\
\hline & 80 & 211 & 351 & 6.99 & & & 544 & 27.5 \\
\hline & 100 & 206 & 351 & 8.63 & & & 513 & 19.2 \\
\hline \multirow{5}{*}{$\begin{array}{l}\text { wt.\% } \\
\text { of SD }\end{array}$} & 20 & 249 & 350 & 1.83 & 428 & 1.46 & 691 & 53.9 \\
\hline & 40 & 232 & 351 & 3.46 & 420 & 1.28 & 612 & 45.9 \\
\hline & 60 & 217 & 351 & 5.14 & 428 & 1.05 & 597 & 38.6 \\
\hline & 80 & 213 & 352 & 6.74 & & & 577 & 30.8 \\
\hline & 100 & 187 & 351 & 8.57 & & & 525 & 23.6 \\
\hline
\end{tabular}
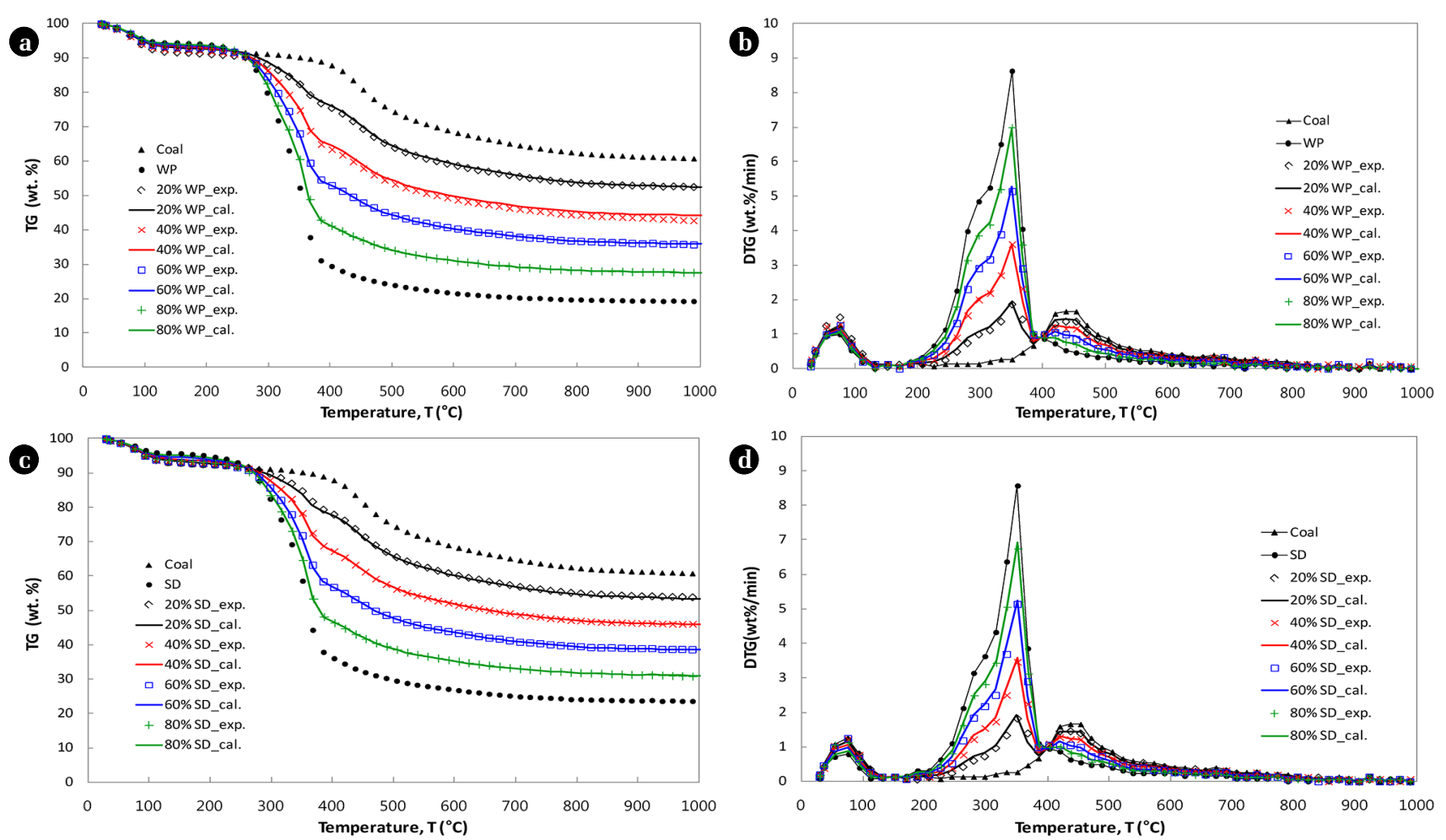

Fig. 3. The experimental and calculated TG and DTG curves for the blends.

the initial temperature (IT) has been used, and defined as the temperature at which the rate of weight loss exceeded 0.3 wt.\%/min. The burnout temperature (BT) is the temperature at which the rate of weight loss decreased to $0.3 \mathrm{wt} . \% / \mathrm{min}$. The temperature at which the rate of weight loss was maximum is defined as peak temperature (PT).

The maximum rates of weight loss at PT, $\left[\mathrm{d}\left(\mathrm{W} / \mathrm{W}_{0}\right) / \mathrm{dt}\right]_{\max }$, is designated as R (wt.\%/min). The values for IT, PT, BT, R and the char yields for the present biomass-coal blends are given in Table 2. The values of IT indicate that the initiation of pyrolysis is an order of SD, WP and coal. The higher R and lower IT values for biomass tell us the biomass has more volatiles and quicker evolution than those of coal. BT indicates that the pyrolysis finish at the temperatures of $513^{\circ} \mathrm{C}-525^{\circ} \mathrm{C}$ for biomass, and $698^{\circ} \mathrm{C}$ for coal. The characteristic temperatures and peak heights for WP and SD are similar since their constituents and compositions are very close to each other.

\subsection{Biomass-coal Blends}

The TG \& DTG curves of WP and SD-coal blends are given in Fig. 3(a) to 3(d), respectively. The curves for parent coal and biomass are also given in the same figures. The calculated weight 
loss of the blends, $W_{\text {cal }}$, is expressed as follows:

$$
W_{c a l}=x_{b} W_{b}+x_{c} W_{c}
$$

where $x_{b}$ and $x_{C}$ are the mass fractions of biomass and coal in the blends, and $W_{b}$, and $W_{c}$ are the weight losses of biomass and coal, respectively.

The calculated rate of weight loss, $(d W / d t)_{c a l}$, is the weighted summation of the individual rate of weight loss, $(d W / d t)_{b}$ and $(d W / d t)_{c}$ for biomass and coal, respectively, and it is given ass:

$$
\left(\frac{d W}{d t}\right)_{c a l}=x_{b}\left(\frac{d W}{d t}\right)_{b}+x_{c}\left(\frac{d W}{d t}\right)_{c}
$$

In Fig. 3(a) to 3(d), the experimental TG and DTG curves (points) for WP and SD-coal blends are compared with the calculated ones (lines). As seen in Fig. 3, the experimental points are almost overlapped with the calculated lines. WP and SD-coal blends exhibited two stages for weight loss (See Fig. 2(b)). The first peaks stem from biomass and the second peaks from coal during the pyrolysis, and their shapes and heights are linearly proportional to the blending ratio. The experimental TG and DTG curves are well described by the calculated curves, which mean the additive rule is quite acceptable for the present biomass-coal blends. In other words, there is no interaction between biomass and coal in the present pyrolysis experiments, and this is further discussed in the following section.

\subsection{Kinetic Parameters}

The activation energies (E) and frequency factors (A) for the present WP and SD-coal blends are given in Tables 3 and 4, respectively. The experimental conversion (x) of the coal and WP are given in Fig. 4(a) and 4(c), together with the fitted conversion data (lines). The respective Arrhenius plots are given in Fig. 4(b) and 4(d). In the cases of SD, the conversion data and Arrhenius plot are quite similar to those for WP, so they are not given in Fig. 6.

The coal pyrolysis behavior is divided into three stages: The first stage ranges up to the conversion of $12 \%$, and the second stage take places in the conversion from $13 \%$ to 58\%. Finally, the third stage shows relatively slow evolution. Table 4 shows the values of $\mathrm{A}$ and $\mathrm{E}$ for three stages. In the second stage, 64 $\mathrm{kJ} / \mathrm{mol}$ and 2,637 $\mathrm{min}^{-1}$ for A and E agree with those of other researcher [20]. The pyrolysis of WP and SD mainly take place up to the conversions of $86 \%$ and $83 \%$ in the temperature range of $152-403^{\circ} \mathrm{C}$, respectively, and then the remnant volatiles are slowly evolved in the second stage. The respective activation energies of 73 and $67 \mathrm{~kJ} / \mathrm{mol}$ and the frequency factors of 725,100 and $65,262 \mathrm{~min}^{-1}$ for WP and SD comparably coincide with the values given by other researchers [20].
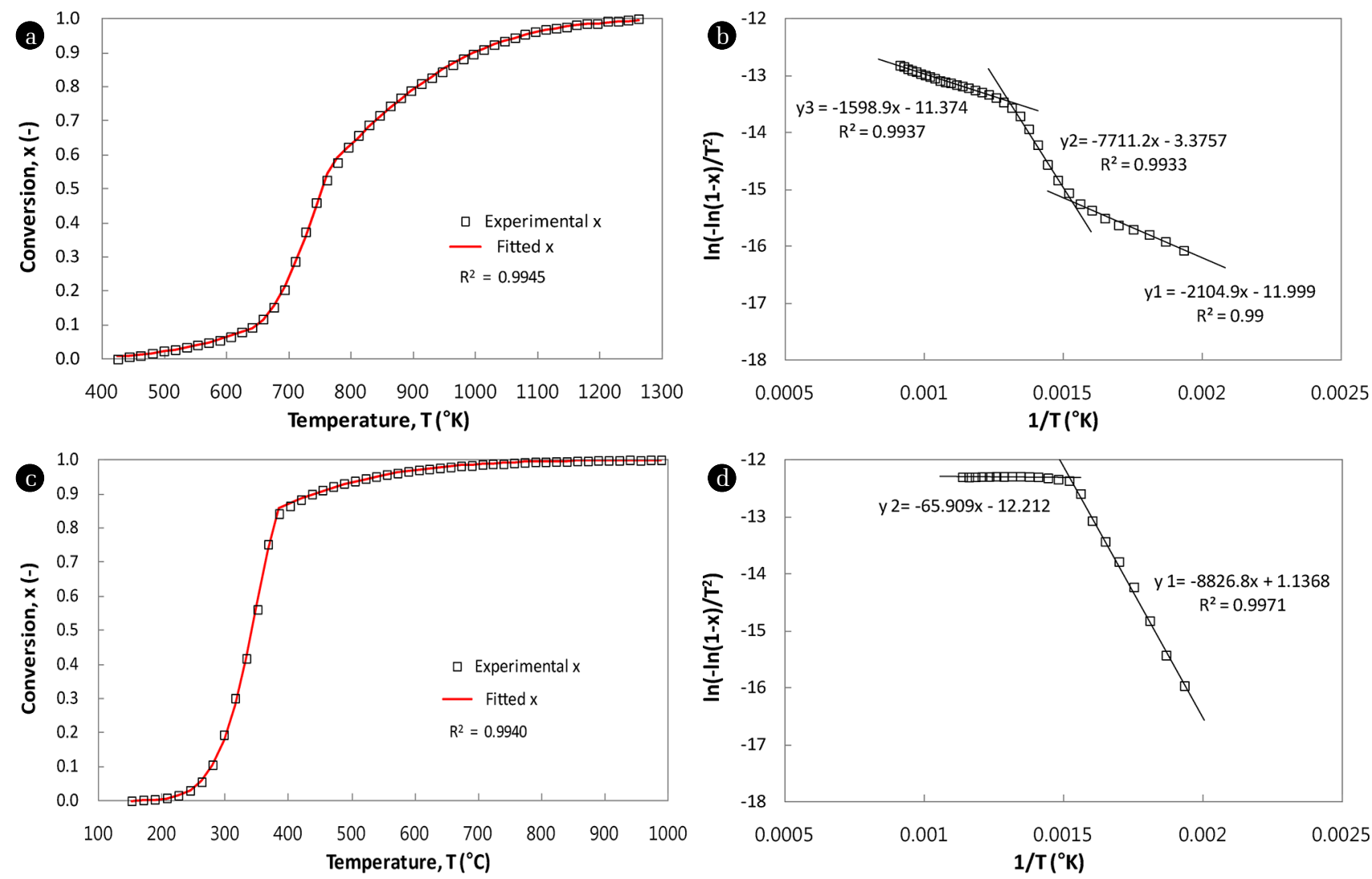

Fig. 4. Conversions and Arrhenius plots for the pyrolysis of coal and WP. 
For the 60:40 and 40:60 WP-coal blends, Arrhenius plots are presented in Fig. 5(a) and 5(b), respectively. In the cases of SD-coal blends, Arrhenius plots are quite similar to those of WP, so they are not given. Fig. 5(a) and 5(b) show that the 60:40 WP-coal blend is adequate to use two stage pyrolysis, while three stages are more acceptable for the 40:60 WP-coal blend. When the percentage of WP and SD decrease from $100 \%$ to $60 \%$ in the blends, the two stages are acceptable, but further decrease shows that

Table 3. Kinetic Parameters for the Pyrolysis of WP-coal Blends

\begin{tabular}{|c|c|c|c|c|c|}
\hline $\begin{array}{c}\text { WP } \\
\text { wt.\% }\end{array}$ & $\begin{array}{c}\text { Temp. } \\
\left({ }^{\circ} \mathrm{C}\right)\end{array}$ & $\begin{array}{c}E \\
(\mathrm{~kJ} / \mathrm{mol})\end{array}$ & $\begin{array}{c}A \\
\left(\min ^{-1}\right)\end{array}$ & $\mathbf{x}$ & $\mathbf{R}^{2}$ \\
\hline \multicolumn{6}{|l|}{ 1st stage } \\
\hline 100 & $152-402$ & 73.39 & 275,100 & $0.0-0.86$ & 0.9964 \\
\hline 80 & $152-402$ & 70.21 & 118,854 & $0.0-0.80$ & 0.9988 \\
\hline 60 & $152-402$ & 66.13 & 40,920 & $0.0-0.73$ & 0.9950 \\
\hline 40 & $152-385$ & 63.10 & 16,902 & $0.0-0.55$ & 0.9972 \\
\hline 20 & $152-385$ & 54.06 & 1,579 & $0.0-0.38$ & 0.9977 \\
\hline (coal) 0 & $152-385$ & 17.50 & 0.13 & $0.0-0.12$ & 0.9900 \\
\hline \multicolumn{6}{|l|}{ 2nd stage } \\
\hline 100 & $403-1,000$ & 0.55 & 0.0027 & $0.87-1.0$ & - \\
\hline 80 & $403-1,000$ & 1.18 & 0.0063 & $0.81-1.0$ & - \\
\hline 60 & $403-1,000$ & 4.73 & 0.0362 & $0.74-1.0$ & - \\
\hline 40 & $386-505$ & 12.24 & 0.25 & $0.56-0.78$ & 0.9806 \\
\hline 20 & $385-488$ & 23.63 & 2.26 & $0.39-0.67$ & 0.9762 \\
\hline (coal) 0 & $386-505$ & 64.11 & 2,637 & $0.13-0.58$ & 0.9933 \\
\hline \multicolumn{6}{|l|}{ 3rd stage } \\
\hline \multicolumn{6}{|l|}{100} \\
\hline \multicolumn{6}{|l|}{80} \\
\hline \multicolumn{6}{|l|}{60} \\
\hline 40 & $506-1,000$ & 2.92 & 0.0141 & $0.78-1.0$ & 0.9582 \\
\hline 20 & $489-1,000$ & 9.05 & 0.0901 & $0.68-1.0$ & 0.9829 \\
\hline (coal) 0 & $506-1,000$ & 13.29 & 0.1837 & $0.59-1.0$ & 0.9937 \\
\hline
\end{tabular}

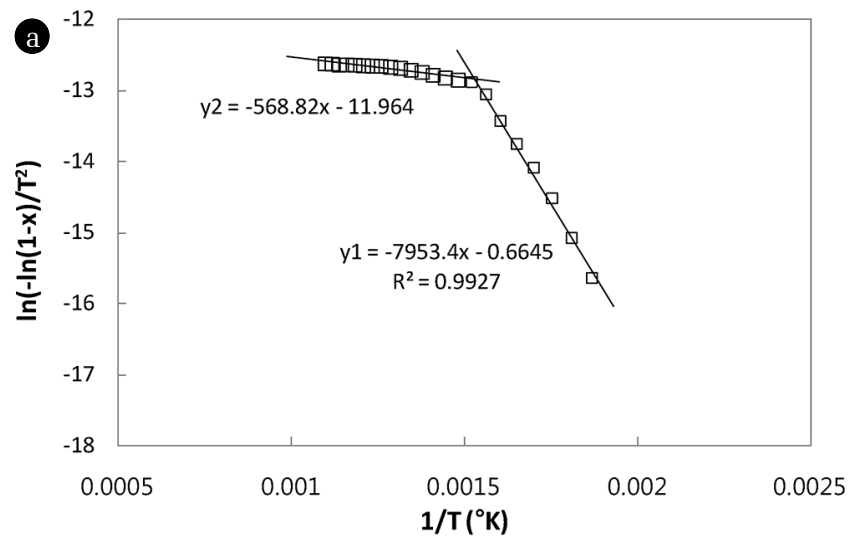

Fig. 5. Arrhenius plots for the pyrolysis of WP-coal blends. three stages are more acceptable to describe the pyrolysis of the blends. The activation energies and frequency factors for WP and SD-coal blends are summarized in Table 3 and 4, stating that the blends which are less than 50\% of WP and SD in the blends follow two stage pyrolysis and the blends exceeded 50\% follow three stage pyrolysis. When the percentage of WP and SD decreases in the blends, values for $\mathrm{A}$ and $\mathrm{E}$ in the first stage have a decreasing trend but increasing trends in the second and

Table 4. Kinetic Parameters for the Pyrolysis of SD-coal Blends

\begin{tabular}{|c|c|c|c|c|c|}
\hline $\begin{array}{c}\text { SD } \\
\text { wt. } \%\end{array}$ & $\begin{array}{c}\text { Temp. } \\
\left({ }^{\circ} \mathrm{C}\right)\end{array}$ & $\begin{array}{c}E \\
(\mathrm{~kJ} / \mathrm{mol})\end{array}$ & $\underset{\left(\mathrm{min}^{-1}\right)}{A}$ & $\mathbf{x}$ & $\mathbf{R}^{2}$ \\
\hline \multicolumn{6}{|l|}{ 1st stage } \\
\hline 100 & $152-403$ & 67.11 & 65,262 & $0.0-0.83$ & 0.9974 \\
\hline 80 & $152-404$ & 66.79 & 50,002 & $0.0-0.75$ & 0.9972 \\
\hline 60 & $152-403$ & 63.70 & 21,804 & $0.0-0.67$ & 0.9972 \\
\hline 40 & $152-385$ & 60.48 & 8,359 & $0.0-0.51$ & 0.9981 \\
\hline 20 & $152-385$ & 47.52 & 335 & $0.0-0.35$ & 0.9968 \\
\hline (coal) 0 & $152-385$ & 17.50 & 0.13 & $0.0-0.12$ & 0.9900 \\
\hline \multicolumn{6}{|l|}{ 2nd stage } \\
\hline 100 & $404-1,000$ & 0.59 & 0.0031 & $0.84-1.0$ & - \\
\hline 80 & $405-1,000$ & 1.43 & 0.0071 & $0.76-1.0$ & - \\
\hline 60 & $404-1,000$ & 4.90 & 0.04 & $0.68-1.0$ & - \\
\hline 40 & $386-505$ & 15.57 & 0.53 & $0.52-0.80$ & 0.9916 \\
\hline 20 & $386-505$ & 27.29 & 4.57 & $0.36-0.70$ & 0.9868 \\
\hline (coal) 0 & $386-505$ & 64.11 & 2,637 & $0.13-0.58$ & 0.9933 \\
\hline \multicolumn{6}{|l|}{ 3rd stage } \\
\hline \multicolumn{6}{|l|}{100} \\
\hline \multicolumn{6}{|l|}{80} \\
\hline \multicolumn{6}{|l|}{60} \\
\hline 40 & $506-1,000$ & 5.87 & 0.0436 & $0.81-1.0$ & 0.9560 \\
\hline 20 & $506-1,000$ & 9.30 & 0.0944 & $0.71-1.0$ & 0.9866 \\
\hline (coal) 0 & $506-1,000$ & 13.29 & 0.1837 & $0.59-1.0$ & 0.9937 \\
\hline
\end{tabular}

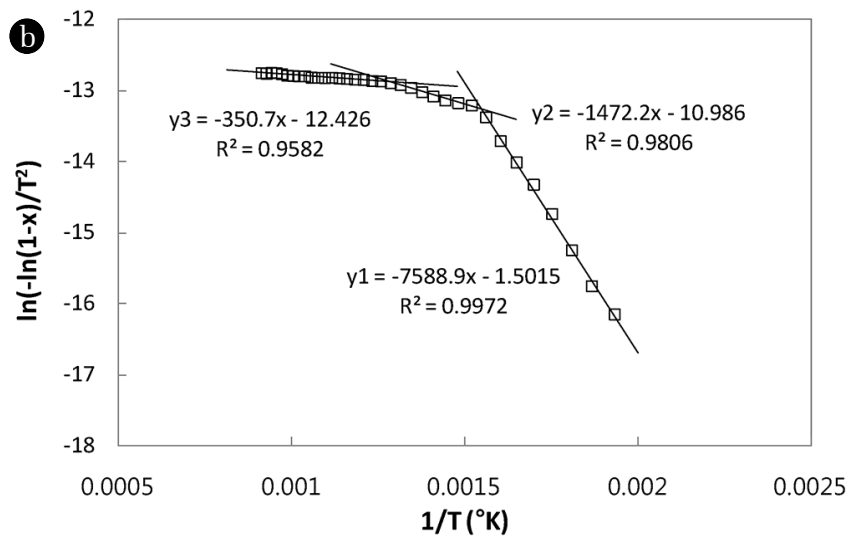


third stages, and this is due to that the activation energy in the first stage mainly attributes to WP and SD pyrolysis. The second and third stages mainly stem from coal. The pyrolysis reactivity of biomass is higher than that of coal, so A and $\mathrm{E}$ decrease with the decrease of biomass in the blend, while the increase of $\mathrm{A}$ and $\mathrm{E}$ in the second and third stages is resulted from the increase of coal in the blend. The linear relationship between the activation energy and blending ratio indicates that the rates of pyrolysis of the present blends do not affected by the rates of individual components, so the pyrolysis of the blends are independent with each component.

\subsection{Interaction between Biomass and Coal in the Blend}

To evaluate the interaction in the blends, it is necessary to check the deviation between the experimental and calculated TG and DTG curves. The characteristic parameters such as char yield, IT, BT, PT and R can be used to investigate the interaction between biomass and coal in the blends.

\subsubsection{Deviation between the experimental and calculated TG and DTG results}

$\mathrm{RMS}_{\mathrm{TG}}$ and $\mathrm{RMS}_{\mathrm{DTG}}$, have been used to evaluate the extent of interaction in the blend [21], and they are given as follows:

$$
\begin{gathered}
R M S_{T H G}=\sqrt{\frac{\sum_{i=1}^{n}\left[\left(W_{e x p}^{i}-W_{c a l}^{i}\right) / W_{c a l}^{i}\right]^{2}}{n}} \\
R M S_{D T G}=\sqrt{\frac{\sum_{i=1}^{n}\left[\left(\frac{d W}{d t}\right)_{e x p}^{i}-\left(\frac{d W}{d t}\right)_{c a l}^{i}\right]^{2} /\left(\frac{d W}{d t}\right)_{\max }^{2}}{n}}
\end{gathered}
$$

where $W_{\text {exp }}$ is the experimental weight of the blends, and $W_{\text {cal }}$ is given by Eq. (8), and $n$ refers to the number of weight data. The term $\left(\frac{d W}{d t}\right)_{\text {exp }}$ is the experimental rate of the weight loss, and $\left(\frac{d W}{d t}\right)_{\text {cal }}$ is given by Eq. (9). The term $\left(\frac{d W}{d t}\right)_{\max }$ is the experimental maximum value in the DTG curve.

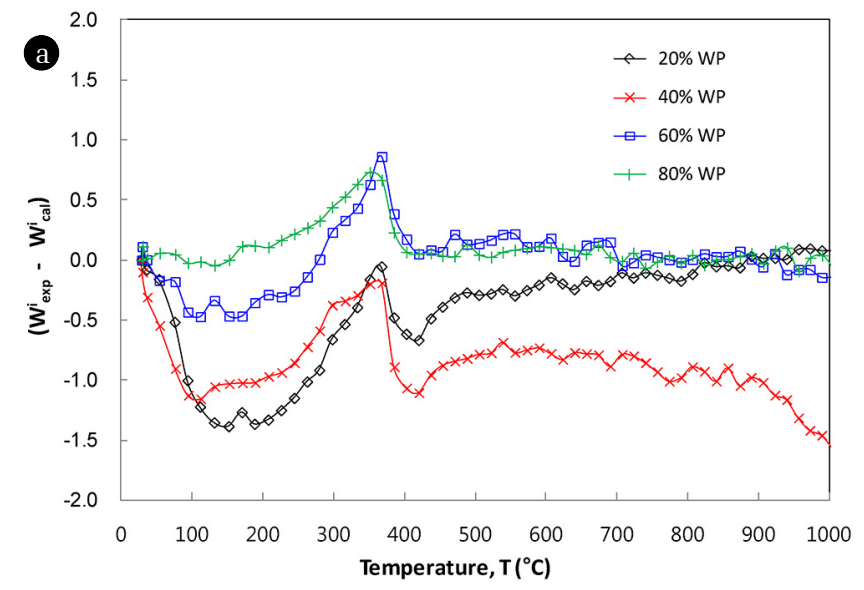

Fig. 6. RMSTG and RMSDTG for WP-coal blends.
Table 5. The Values of RMSTG and RMSDTG for Biomass-coal Blends

\begin{tabular}{clllll}
\hline \multirow{2}{*}{$\begin{array}{c}\text { wt.\% of } \\
\text { biomass }\end{array}$} & \multicolumn{2}{c}{ RMS_TG } & & \multicolumn{2}{c}{ RMS_DTG } \\
\cline { 2 - 3 } \cline { 5 - 6 } & WP & SD & & WP & SD \\
\hline 20 & 0.7 & 0.7 & & 4.3 & 3.8 \\
40 & 1.7 & 0.4 & & 2.4 & 2.7 \\
60 & 0.4 & 0.6 & & 1.4 & 1.9 \\
80 & 0.4 & 0.7 & & 0.8 & 1.1 \\
\hline
\end{tabular}

The values of $\mathrm{RMS}_{\mathrm{TG}}$ and $\mathrm{RMS}_{\mathrm{DTG}}$ for the present $\mathrm{WP}$ and SD-coal blends are summarized in Table 5. Fig. 6 shows the values of $\left(W_{e x p}^{i}-W_{c a l}^{i}\right)$ and $\left(\frac{d W}{d t}\right)_{e x p}^{i}-\left(\frac{d W}{d t}\right)_{c a l}^{i}$ for WP-coal blends. At the tested temperature ranges, there are no abrupt and distinct variations in the $\mathrm{RMS}_{\mathrm{TG}}$ and $\mathrm{RMS}_{\mathrm{DTG}}$ curves. The samples of SD-coal blends show the similar variation in their curves. The $\mathrm{RMS}_{\mathrm{TG}}$ values for WP and SD-coal blends are all less than $0.7 \%$ except for 1.7\% for 40:60 WP-coal blend. As seen in Fig. 6(a) and Table 5 , the values of $\left(W_{e x p}^{i}-W_{c a l}^{i}\right)$ for all blends are almost within $\pm 2.3 \%$, which are relatively small values when comparing them to the values of $17.4 \%$ [20] and $11.09 \%$ [22]. The present values are quite reasonable to be accepted as no-interaction between two components in the blends. The evidence of no-interaction between the present biomass-coal blends can be seen in the values of $\mathrm{RMS}_{\mathrm{DTG}}$ in Table 5 and $\left(\frac{d W}{d t}\right)_{\text {exp }}^{i}-\left(\frac{d W}{d t}\right)_{\text {cal }}^{i}$ in Fig. 6(b). The values of RMS ${ }_{\text {DTG }}$ for WP and SD-coal blends are ranged from 0.8 to $4.4 \%$, which are reasonable values compared to $6 \%$ given by the independent parallel reaction scheme of other researcher [20]. The values of $\left(\frac{d W}{d t}\right)_{\text {exp }}^{i}-\left(\frac{d W}{d t}\right)_{\text {cal }}^{i}$ in Fig. 6(b) are almost remained within \pm 0.4 for all blends, which is thought to be no-interaction in the present biomass-coal blends.

\subsubsection{Char yields}

If there is no interaction between biomass and coal in the blend, the char yields of the blend would be an arithmetic average of

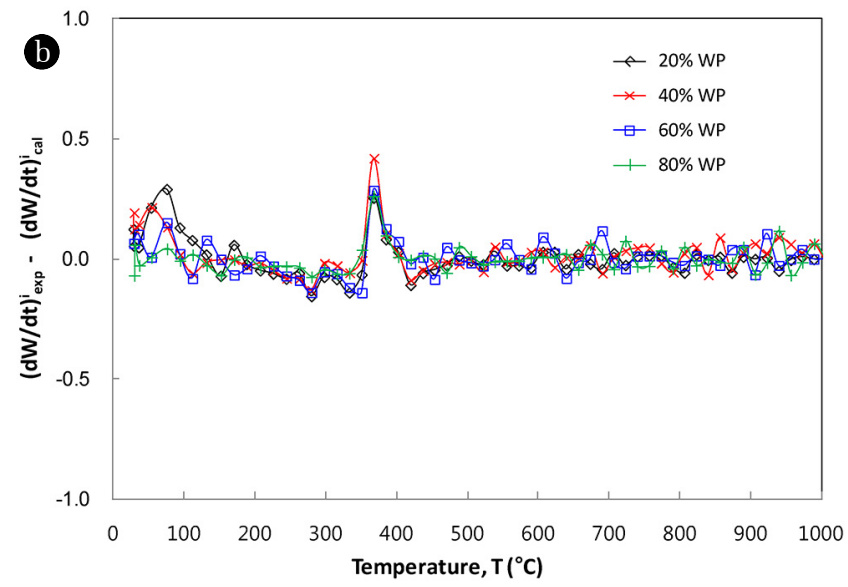




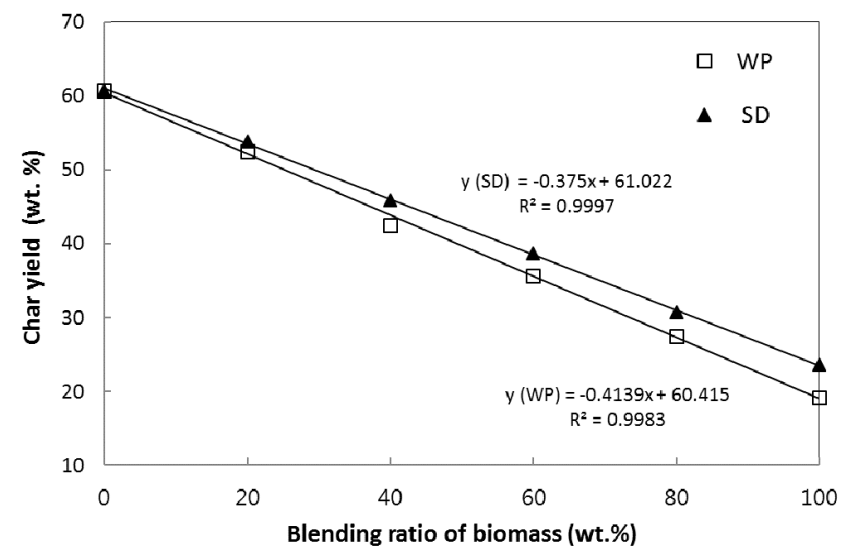

Fig. 7. Char yield against the blending ratio.

the individual char yield in additive manner, namely, a linear relationship between the char yield and the blending ratio. The present char yields of coal, WP, SD and their blends depending on the blending ratio are plotted in Fig. 7, and the linear relationship between the present biomass and coal indicate no-interaction. The linear relationship between the char yields and the blending ratio is consistent with the results of other researchers $[5,7,9]$

\subsubsection{Maximum reaction rates and characteristic temperatures}

The variation of the characteristic temperatures and the maximum reaction rates depending on the blending ratio is worthwhile to check the interaction in the biomass-coal blends. As shown in Table 2, the first peak temperatures $\left(\mathrm{PT}_{1}\right)$ are remained within $\pm 1.0^{\circ} \mathrm{C}$ at $351^{\circ} \mathrm{C}$ for WP and SD-coal blends. Fig. 8 shows the variations of peak heights depending on the blending ratio. As explained above, the maximum rates of weight loss at PT, $\left[\mathrm{d}\left(\mathrm{W} / \mathrm{W}_{0}\right) / \mathrm{dt}\right]_{\max }$, is designated as the peak height, $\mathrm{R}$ (wt.\%/min). The first peak heights $\left(\mathrm{R}_{1}\right)$ are varied linearly with the blending ratio. The second peaks for WP and SD-coal blends are appeared at the blending ratios of 20:80, 40:60 and 60:40, and their peak heights $\left(\mathrm{R}_{2}\right)$ linearly decrease with increase of WP and SD percentages in the blends. The peak temperatures $\left(\mathrm{PT}_{2}\right)$ for $\mathrm{WP}$ and SD are remained at $445^{\circ} \mathrm{C}$ and $428^{\circ} \mathrm{C}$, respectively. The constant peak temperatures $\left(\mathrm{PT}_{1}\right.$ and $\left.\mathrm{PT}_{2}\right)$ are originated from biomass and coal, respectively, and the peak heights $\left(R_{1}\right.$ and $\left.R_{2}\right)$ are linearly proportional to the blending ratio. This shows that the pyrolysis of coal and biomass in the blend occur independently.

As given in Table 2 and Fig. 8, the biomass-coal blend pyrolysis starts around $211-213^{\circ} \mathrm{C}$. The ITs of the blends decrease gradually with the increase of biomass percentage in the blends. The present biomass has BT of $513-577^{\circ} \mathrm{C}$, and the increase of biomass percentage in the blends leads to decrease of the BT. The present relationship of IT and BT with the blending ratio is consistent with the findings of other researchers [7, 22]. From the characteristic temperatures and the peak heights in Fig. 5(a) and 5(b), it can be concluded that there are no-interactions in the pyrolysis of the present biomass-coal blends.

Overall, the no-interaction between the individual components in the blends has appeared, and it means that the rates of pyrolysis

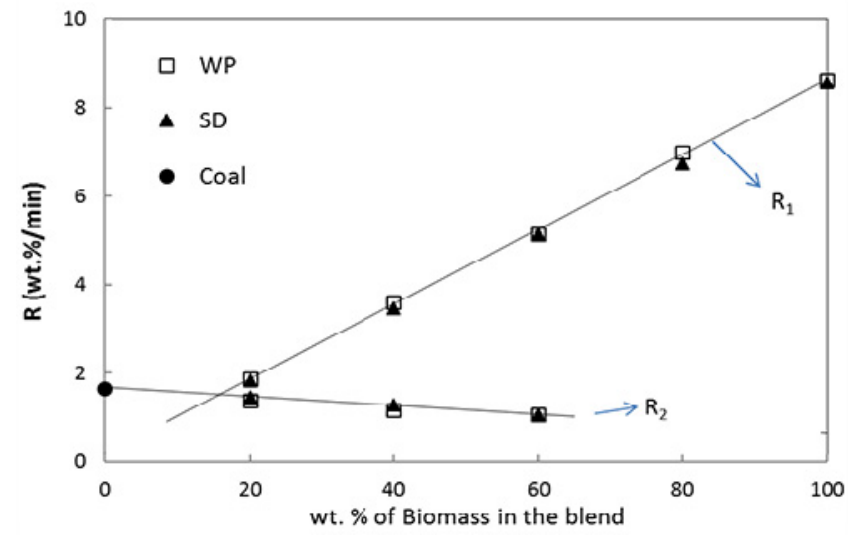

Fig. 8. Peak heights against the blending ratio.

for the present biomass and coal do not affect each other. However, overall combustion efficiencies of the blends would be varied with the combustion of volatiles and char resulted from the pyrolysis.

\subsubsection{Lignocellulose components in the blends}

Among lignocellulosic components, cellulose has exhibited the positive effects on the pylolysis behavior of its blends with bituminous coal, while hemicelluloses and lignin, the positive or negative effects depend on the blending ratio and reaction temperature range, as reported by $\mathrm{Wu}$ et al. [15]. For example, the addition of cellulose (25\%, $50 \%$ and $75 \%$ ) to bituminous coal resulted in the positive effect in their blends, which means the acceleration of decomposition of bituminous coal in the temperature range above $360^{\circ} \mathrm{C}$. For hemicellulose, the negative effects were showed with the blends of $25 \%, 50 \%$ and $75 \%$ hemicellulose and bituminous coals over the temperature range of $200-950^{\circ} \mathrm{C}$. The adding of lignin to bituminous coal yielded the positive effect under $50 \%$ and $75 \%$ lignin percentage in the blends from room temperature to $950^{\circ} \mathrm{C}$, while the $25 \%$ addition of lignin to bituminous coal resulted in the positive effect for the pyrolysis of bituminous coal. In the studies of $\mathrm{Wu}$ et al. [15], the positive or negative effects with the addition of lingocellulose components in the blends were explained with the increases diffusion of volatiles on the cellulose and coal, blocking effect on the volatile evolution of the blends, and the swelling of lignin component with some melting and blocking of the pore. They mentioned that three main components may compete against each other during the pyrolysis, so the synergistic effects in the blends may depends on the competition effects of three model components.

For the present biomass-coal blends, three lignocellulose components are all remained under about 25 wt.\% in the blends. For example, the 80:20 WP-coal blend showed that the respective mass percentages of cellulose, hemicellulose and lignin in the blend are about 20\%, 13\% and 21\%. For the 80:20 SD-coal blend, they are about $22 \%, 13 \%$ and $15 \%$, respectively. All samples tested in this study, the weight percentages of lignocellulose components are all under 25\% (See Table 1). According to the results on the degree of synergistic effect expressed in terms of $\Delta W=$ $W_{\text {exp }}-W_{\text {cal }}$, the positive effect was revealed for $25 \%$ cellulose and 
25\% lignin components blended with $75 \%$ bituminous coal, while the blend of $25 \%$ hemicellulose and $75 \%$ bituminous coal yielded the negative effect. Their relative sensitivities of cellulose, hemicellulose and lignin on the positive $(+)$ and negative $(-)$ effect are calculated to be $-1.03,+1.0$ and -2.15 . The no-interaction between the present biomass-coal blends might be the overall competition of positive and negative effects of lignocellulose components which are mostly under 25 wt.\% in the present blends. Since the positive and negative effects varied with the blending ratio and temperature range, further studies for the effects of lignocellulose components on the synergies in the biomass-coal blends are necessary.

\section{Conclusions}

In this study, the pyrolysis characteristics of biomass-coal blends have been examined through thermogravimetric analysis. WP and SD were blended with bituminous coal. The interaction between biomass and bituminous coal in the blend was evaluated in terms of the maximum rate of weight loss, characteristic temperatures, char yields, and the calculated and experimental thermogravimetric curves.

For the biomass-coal blends, the first peaks came from biomass and the second peaks came from coal. The calculated TG and DTG curves of the blends well coincide with the experimental curves, and the deviations between the experimental and calculated TG and DTG curves were very small. The linear relationship between the blending ratio and char yields is presented for the present biomass-coal blends, and the peak height gave the linearity against the blending ratio.

The kinetic data for the present biomass-coal blends were obtained with the Coats and Redfern equation. The activation energy and frequency factor for the biomass-coal blends are linearly proportional to the blending ratio. The lignocellulose components in the present blends are evaluated to assess the interaction, and the competition among components needs to be further studied. From the TGA results, it has concluded that there is no significant interaction in the present biomass-coal blends.

\section{Acknowledgements}

This work was supported by KOWEPO (Korea Western Power Co.), EWPC (Korea East-West Power Co.), and Korea Electric Power Corporation (KEPCO) funded by project No. R15GF04.

\section{References}

1. Fernando R. Fuels for biomass cofiring. IEA Clean Coal Centre, CCC/102; 2005.

2. Fernando R. Cofiring high ratios of biomass with coal. IEA Clean Coal Centre, CCC/194; 2012.

3. Pan YG, Velo E, Puigjaner L. Pyrolysis of a blend of biomass with poor coals. Fuel 1996;75:412-418.

4. Kastanaki E, Namnuka D, Grammelis P, Kakaras E.
Thermogravimetric studies of the behavior of lignite-biomass blends during devolatilization. Fuel Process. Technol. 2002;77-78:159-166.

5. Meesri C, Moghtaderi B. Lack of synergistic effects in the pyrolytic characteristics of woody biomass/coal blends under low and high heating rate regimes. Biomass Bioenerg. 2002;23:55-66.

6. Biagini E, Lippi F, Petarca L, Tognotti L. Devolatilization rate of biomasses and coal-biomass blends: An experimental investigation. Fuel 2002;81:1041-1050.

7. Vuthaluru HB. Thermal behavior of coal/biomass blends during co-pyrolysis. Fuel Process. Technol. 2003;85:141-155.

8. Vamvuka D, Pasadakis N, Kastanaki E, Grammelis P, Kakaras E. Kinetic modeling of coal/agricultural by-product blends. Energ. Fuel. 2003;17:549-558.

9. Moghtaderi B, Meesri C, Wall TF. Pyrolytic characteristics of blended coal and woody biomass. Fuel 2004;83:745-750.

10. Zhang L, Xu S, Zhao W, Liu S. Co-pyrolysis of viomass and coal in a free fall reactor. Fuel 2007;86:353-359.

11. Haykiri-Acma H, Yaman S. Synergy in devolatilization characteristics of lignite and hazelnut shell during co-pyrolysis. Fuel 2007;86:373-380.

12. Ulloa CA, Gordon AL, Garcia XA. Thermogravimetric study of interactions in the pyrolysis of blends of coal with radiate pine sawdust. Fuel Process. Technol. 2009;90:583-590.

13. Seo MW, Goo JH, Kim SD, Lee SH, Choi C. Gasification characteristics of coal/biomass blend in a dual circulating fluidized bed reactor. Energ. Fuel. 2010;24:3108-3118.

14. Haykiri-Acma H, Yaman S. Interaction between biomass and different rank coals during co-pyrolysis. Renew. Energ. 2010;35:288-292.

15. Wu Z, Wang S, Zhao J, Chen L, Meng H. Synergistic effect on the thermal behavior during co-pyrolysis of lignocellulosic model components blend with bituminous coal. Bioresour. Technol. 2014:169:220-228.

16. Muthuraman M, Namioka T, Yoshikawa K. A comparative study on co-combustion performance of municipal solid waste and Indonesian coal with high ash Indian coal: A thermogravimetric analysis. Fuel Process. Technol. 2010;91:550-558.

17. Fang X, Jia L, Yin L. A weighted average global process model based on two-stage kinetic scheme for biomass combustion. Biomass Bioenerg. 2013;48:43-50.

18. Oyeedun AO, Tee CZ, Hanson S, Hui CW. Thermogravimetric analysis of the pyrolysis characteristics and kinetics of plastics and biomass blends. Fuel Process. Technol. 2014;128:471-481.

19. Sandip Gangil Dominant thermogravimetric signatures of lignin in cashew shell as compared to cashew shell cake. Bioresour. Technol. 2014;155:15-20.

20. Lu KM, Lee WJ, Chen WH, Lin TC. Thermogravimetric analysis and kinetics of co-pyrolysis of raw/torrefied wood and coal blends. Appl. Energ. 2013;105:57-65.

21. Anca-Couce A, Berger A, Zobel N. How to determine consistent biomass pyrolysis kinetics in a parallel reaction scheme. Fuel 2014;123:230-240.

22. Meng H, Wang Sm Chen L, Wu Z, Zhao J. Thermal behavior and the evolution of char structure during co-pyrolysis of platanus wood blends with different rank coals from northern China. Fuel 2015;158:602-611. 